\title{
Ela: \\ o amor nos filmes e pelos filmes
}

\section{Carolina Oliveira do Amaral ${ }^{1}$}

\begin{abstract}
Resumo:Aproveitando-se da atmosfera de encanto própria do romantismo e do cinema, pretende-se aproximar as ideias de amor romântico e espectatorialidade através da análise do filme Ela (Her, Spike Jonze, EUA, 2013), em que um homem e seu sistema operacional se apaixonam. O filme se destaca pelas opções distintas na representação do amor e da intimidade: a mulher, sem corpo nem face, é construída apenas pelo sua voz. Os entrelaçamentos passam também por uma discussão sobre a tecnologia, tanto na história, quanto no nosso envolvimento enquanto espectadores de cinema.
\end{abstract}

Palavras-chave: Ela; amor romântico; espectatorialidade; tecnologia.

\begin{abstract}
Bringing together the magic within romantism and cinema, through the analysis of Her (Spike Jonze, EUA, 2013), this essay aims to approximate the ideas of romantic love and spectatorship. The feature film - about a man and his operational system falling in love - make new choices in representing love and intimacy: the woman has no face or body and the character is constructed only by her voice. The interconexions pass through discussions about technology in the story and our roles as cinematic spectators.
\end{abstract}

Keywords: Her; romantic love; spectatorship; technology.

"Você me acha louco?

Acho que todo mundo que se apaixona é louco. Uma espécie de loucura temporária tolerada socialmente.”

O diálogo acima é do filme Ela (Her, Spike Jonze, EUA, 2013) cuja história trata de Theodore (Joaquim Phoenix), um homem que se apaixona por seu sistema operacional, Samantha (voz de Scarlett Johansson), e o relacionamento deles. O casal, composto por um homem e uma tecnologia, é desenvolvido como em tantos outros filmes românticos: os dois se conhecem, se tornam amigos, trabalham juntos,

\footnotetext{
1 Doutoranda em Comunicação Social pelo PPGCOM-UFF. Email:carolinaoamaral@gmail.com.
} 
até que a convivência diária se transforma em paixão e amor. Samantha é engraçada, sexy, inteligente, interessada em seu parceiro, resumindo, a mulher perfeita, exceto por um pequeno detalhe: Samantha é um sistema operacional, uma espécie de inteligência artificial, sem corpo, se constitui apenas de bits e bytes programados para se comportar como um ser humano e assumir uma personalidade própria.

A trama principal desenvolve-se a cerca dos sentimentos entre Theodore e Samantha. Seria real o que eles sentem? Seria loucura? Na tradição ocidental é comum o paralelo entre amor e feitiço, amor e loucura, como se o estado de fascinação romântica fosse realmente um estado de suspensão da consciência, metáforas também frequentemente associadas ao ato de se assistir a um filme. Tristão e Isolda provaram "uma poderosa porção com ervas e flores" misturadas com vinho, formando uma "tintura ervosa, que era um filtro de amor capaz de fazer nascer a paixão no homem e na mulher que bebessem" (1990, p. 44). As comédias românticas, cujo principal tema é o poder do amor sobre os personagens, apresenta exemplos semelhantes como Porção de amor número 9 (Love portion number 9, Dale Launer, EUA, 1992), Da magia à sedução (Practical Magic, Griffin Dune, EUA, 1998), A feiticeira (Bewitched, Nora Ephron, EUA, 2005) e Quando em Roma (When in Rome, Mark Steven Johnson, EUA, 2010) com truques diferentes que apaixonam casais através da magia.

Por outro lado, podemos compilar teorias que comparam a espectatorialidade ao sonho e o espectador a alguém que se entrega ao sonho, como se houvesse uma "perda da consciência habitual" (SMITH, 2005, p.141). Amor como feitiço, cinema como sonho. Metáforas que associam ambos a um estado que questione a realidade ou, no mínimo, sua racionalidade. "Não é amor, o que tende à realidade" diz o provérbio cortês lembrado por Denis de Rougemont em livro sobre Tristão e Isolda. Também Barthes (1987, p. 51) ao fundar a prática da leitura no prazer, concebe o lersonhar.

É possível estabelecer uma ligação entre o romance e a cinefilia, como Bazin (apud Sutton) faz ao atribuir ao cinema, dentre todas as artes, aquela que mais particularmente é constituída por amor. Frente a uma tecnologia aprendemos a amar e odiar e nos misturamos ao que assistimos enquanto dura o filme. 
Paul Sutton (2009) se propõe a analisar essa relação entre amor, em especial, comédias românticas, e espectatorialidade, através da forma de amor privilegiada por essas narrativas: o amor à primeira vista. Segundo o autor, o amor à primeira vista ideal para a economia temporal do filme, além de se encaixar perfeitamente à estrutura plano/contraplano - espetaculariza o ato de se apaixonar. O conceito de afterwardness, que segundo a psicanalítica de Laplanche, propõe uma estrutura temporal em que as experiências traumáticas só podem ser compreendidas posteriormente, quando o trauma é desfeito, seria usado para entender também o amor à primeira vista, em francês coup de foudre, que literalmente seria "tiro de relâmpago", ligando mais uma vez a idéia de amor e trauma, après coup em francês. O amor, assim como o trauma, só poderia ser compreendido a posteriori, num momento que ressignificaria aquele marco inicial. Também através de uma temporalidade posterior, a espectatorialidade funcionaria (ibdem, p.42):

Quero argumentar aqui que os espectadores refazem os filmes como parte do processo de espectatorialidade e além da experiência cinemática real, eles carregam consigo um "filme" refeito e relembrado. Essa visão de espectatorialidade, dessa forma, toma afterwardness como sua força motriz ${ }^{2}$.

A aproximação nos interessa ainda que as explicações psicanalíticas se alonguem além de nossas preocupações. O importante é a ideia de uma experiência espectatorial caracterizada por reconstrução, criatividade e articulada por amor, diferente da crença de que o espectador é alguém alheio a si próprio e ao que vê. Tradicionalmente, a teoria do cinema estudou o fenômeno da espectatorialidade sob o viés psicológico da "identificação", mais tarde sofisticada por Edgar Morin como “projeção-identificação”. Béla Balázs (1983, p. 85) explica que "estamos no filme” porque "nosso olho, e com ele nossa consciência, identifica-se com os personagens no filme; olhamos para o mundo com os olhos deles, e por isso, não temos nenhum ângulo de visão próprio”. Morin (1983, p. 147) explica que a projeção-identificação seria uma participação afetiva, na qual o espectador se identifica com os atores e se projeta naquela realidade ficcional. Segundo ele, "o sonho é projeção-identificação em estado puro".

2 Tradução nossa, assim como todas as traduções dos livros em inglês presentes no texto. 
O que argumentam Murray Smith e Sutton é uma espectatorialidade enquanto experiência criativa. Smith condena o que chama "metáforas do engano" cinema/sonho, cinema/hipnose - nas quais, o envolvimento entre o espectador e o filme necessita, ainda que, temporariamente, que os espectadores acreditem ser real a representação ficcional. Smith esclarece que o espectador e o filme narrativo encontra-se junto à instituição da ficção, e que estaríamos sempre perifericamente atentos a isso, pois são "modos não conflitantes de consciência"; a ficção nos afeta porque nos entretêm imaginativamente. Por sua vez, Sutton (ibdem, p.51) acredita que o espectador deve se apaixonar pelo filme num ato violento, "ser sequestrado pela imagem". Relembrar e refazer o filme que agora pertence às suas próprias experiências. Se Smith vê o filme como quase-experiêriência que estimula a imaginação, Sutton acredita ser o amor um ato imaginativo estimulando a espectatorialidade que "re-traduz" o filme numa "auto-tradução". Há uma dimensão performativa na espectatorialidade que "recria o filme lembrado e articula com um certo amor à primeira vista (sempre quase à segunda vista) pelo cinema" (SUTTON, ibdem, p.43).

Sutton tensiona a fascinação do amor à primeira vista com um amor relembrado e refeito pela espectatorialidade. Sendo assim, o lampejo de amor, o golpe, ainda que instantâneo só poderia ser construído narrativamente em retrospecto ao final do filme. Distanciando-se da ideia de feitiço ou magia, Sutton coloca o amor, mesmo aquele repentino, num processo narrativo. $\mathrm{O}$ encantamento com a tela e com filmes de amor se inscreveriam no mesmo processo estabelecido narrativamente.

É narrativamente que se engajam espectador e histórias de amor, num entrecruzamento já antigo como nos mostra Giddens (1993, p.50):

O amor romântico introduziu a ideia de uma narrativa para a vida individual - fórmula que se estendeu radicalmente a reflexividade do amor sublime. Contar uma história é um dos sentidos do "romance", mas esta história tornava-se agora individualizada, inserindo o eu e o outro em uma narrativa pessoal, sem ligação particular com os processos sociais mais amplos. O início do amor romântico coincidiu mais ou menos com a emergência da novela: a conexão era a forma narrativa recém-descoberta.

Nosso objetivo é refletir sobre histórias de amor e espectatorialidade, que consideramos também uma relação amorosa. Conforme Giddens afirmou, o que liga 
o amor romântico e as novelas de amor, surgidos mais ou menos na mesma época, é justamente a forma narrativa em comum, o "romance". Buscamos mostrar de que maneira o amor se constrói narrativamente no filme Ela, uma história de amor entre um homem e uma tecnologia, para alcançar, de alguma forma, o espectador.

\section{Voz e narrativa}

Filmes românticos costumam mistificar o amor, desde o início: o apaixonar-se como um golpe, uma força da natureza, um ato de violência, uma virada narrativa. Entretanto, poucos romances cinematográficos se perguntam se é realmente sobre amor que se fala. Ela se preocupa em entender e aceitar esse amor que vemos na tela. O filme se passa num futuro próximo. Imagina uma Los Angeles contrastando arranha-céus apertados, com apartamentos espaçosos e passarelas amplas em que as pessoas caminham, usam os transportes públicos e conversam com a tecnologia.

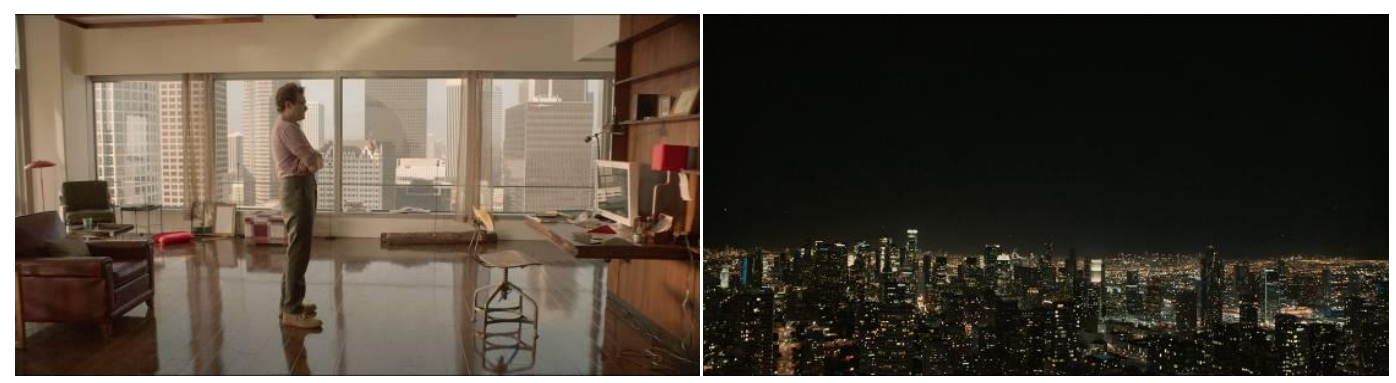

Figura 1 e Figura 2:Los Angeles do Jonze: espaços vazios internos, com o horizonte congestionado

Fonte: Sony Pictures

A tecnologia fala e ouve e é através dela que o filme exercita sua capacidade de imaginar o futuro, assumindo melhor o seu caráter de ficção científica. No começo, Theodore dá ordens ao seu computador, cuja voz maquínica executa continuamente os comandos. Ele trabalha na empresa "Beautiful Handwritten Letters dot com3" escrevendo belas cartas de amor para outras pessoas. Theo tem um talento especial de colocar em palavras sentimentos alheios para os seus entes queridos, ditando para um computador que simula a letra à mão. Porém, distante de todo amor ditado ao longo do dia, Theodore sofre com o relacionamento desfeito e costuma ficar só. Tudo muda quando ele adere à tecnologia OS1, uma espécie de inteligência artificial,

3 Que ironicamente significa "Lindas cartas manuscritas ponto com". 
programada para ser intuitiva e se desenvolver como uma pessoa. Assim ele conhece Samantha.

Em geral, os dois apaixonados se olham e se admiram sem precisarem dizer qualquer palavra. Presente desde o cinema silencioso, a estratégia tem como seu principal veículo a imagem da mulher apaixonada e desejada, em closes e cortes sensuais. Ela constrói sua narrativa pelo andamento do romance entre Theodore e Samantha, no entanto, o filme não se farta de imagens do casal que está apaixonado. Samantha não tem rosto, não tem corpo, Samantha é uma voz. Se na maioria dos filmes, o corpo e o rosto femininos são veículo da sedução erótica, em Ela, o espetáculo é criado pela voz. A atriz Scarlett Johasson se encaixa no tipo que normalmente encarna no cinema hegemônico papéis femininos em histórias de amor. É possível, para os espectadores que a reconhecem, estabelecer um vínculo imaginário entre a imagem da atriz e a voz de Samantha. E ainda que Johasson não apareça, a voz evoca a presença do rosto e do corpo da atriz tão conhecidos e explorados por outros filmes como elemento central da sedução. Assim, o filme reconstrói estratégias exibicionistas do cinema, ao que Laura Mulvey acredita serem capazes de levar o filme "a uma terra de ninguém", com a imagem espetacular da mulher interrompendo o fluxo narrativo, numa contemplação sensual (MULVEY, 1983, p. 444):

em seu papel tradicional exibicionista, as mulheres são simultaneamente olhadas e exibidas, tendo sua aparência codificada no sentido de emitir um impacto erótico e visual de forma a que se possa dizer que conota a sua condição de "para-ser-olhada.

Samantha não aparece, é apenas intuída, o que pode causar um desconforto no espectador, semelhante ao de Theodore que quase pode ver sua presença.

A cena de sexo que inicia o romance entre os dois também só pode ser ouvida, enquanto o filme sustenta uma tela preta. Há uma interdição desse corpo, propensa a abalar a máxima do ensaio de Mulvey, que atribui ao homem o olhar e à mulher a imagem/espetáculo, objeto do olhar, recortado e controlado por quem olha. No filme, a imagem mostrada é sempre de Theodore. 

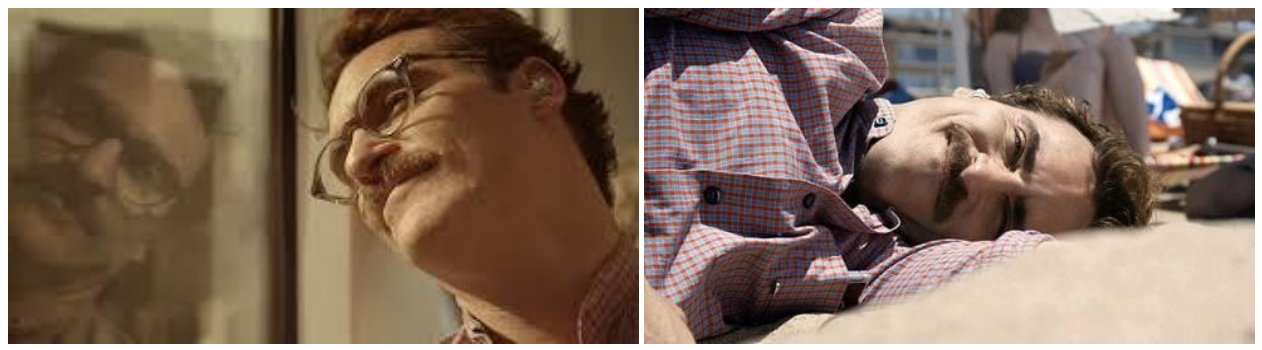

Figura 3 e Figura 4: Imagens do encantamento centradas na figura masculina.

Fonte: Sony Pictures

São as reações dele, o modo como ele parece se divertir e se "enfeitiçar", ou até mesmo lembrar suas experiências passadas de amor que dão feição ao filme. Mulvey explora a ideia de que a mulher é colocada no cinema hegemônico como objeto de olhar, fonte do prazer escopofílico de olhar e ser olhado. Por se tratar de uma teoria que conjuga espectatorialidade e a determinação de papeis específicos para os gêneros, o ensaio enriquece a nossa análise que recorre ao filme como um contraponto. Os planos bem próximos do ator, incluindo o que estampa o cartaz do filme, exibem o seu rosto, a principal imagem do amor em tela. É dele a potência do close-up, normalmente dirigida ao gênero feminino. É dele "a expressão facial do rosto completa e compreensível em si mesma" (BALÁZS, 1983 , p. 93) na qual enxergamos o amor.

Steven Cohan problematiza a questão discutida por Mulvey, através da figura de Fred Astaire, que segundo o autor, sempre foi objeto de um explícito olhar erótico. O musical, que exibiu sem pudores corpos masculinos performando, seria responsável por imaginar uma outra masculinidade, baseada no espetáculo. Ela abusa dos momentos de contemplação do rosto de Phoenix; é ele quem vemos dançar e cantar num momento de puro contentamento amoroso.

A menção ao musical nos parece válida mais uma vez porque é através da música que Samantha tenta exprimir seus sentimentos mais íntimos. Seja buscando as que já existem, ou compondo peças novas. Rick Altman (1989) argumenta ser o musical o único gênero a desequilibrar a habitual hierarquia cinematográfica imagem/som. Segundo o autor, a imagem refletiria a música em todas as suas qualidades pictóricas, através de uma subordinação da história ao que se ouve na trilha. Samantha acredita que as canções que compõe podem servir com uma 
fotografia dos momentos que passaram juntos. A música seria uma forma de registrar o amor, e até a imagem de Samantha.

No auge do envolvimento entre os dois, Samantha e Theodore cantam juntos "The moon song", um dueto que mostra a sintonia entre os dois, com o mesmo papel que desempenham em filmes musicais, associando amor e música. A canção coincide com o momento em que Theodore e Samantha viajam de férias para um chalé na neve, ápice do romance que a partir daí começa a sofrer fissuras devido aos novos desafios que agora Samantha experencia4.

Em Ela, a importância da trilha não é dada somente pelas incursões musicais, mas, sobretudo, pela a voz de Samantha, e pelos diálogos traçados. Sendo o corpo humano a medida do lugar que se ocupa, a voz de Samantha, livre de um corpo que a ancore, é capaz de tudo presenciar. É a própria voz que determina o território de Samantha, e dada a capacidade do som de ser onidirecional, ela acaba por ocupar todos os espaços.

Acusmática (CHION, 2004, p. 32) é a voz que vaga pela tela buscando um lugar para se deter: "quando a presença acusmática é a de uma voz e, sobretudo, quando ainda não se viu a voz, quando ainda não se pode assimilá-la a um rosto, temos um tipo particular, uma espécie de sombra falante e atuante, ao que chamamos acusmaser, ou seja, um ser acusmático”. Há no cinema um jogo de mostrar, não mostrar ou mostrar parcialmente a fonte do som, mas o próprio Chion admite que, em geral, a voz encontra o seu rosto e corpo, havendo assim uma "desacusmatização". No filme, há uma única tentativa, de "desacusmatizar" a voz, quando uma voluntária se propõe a ser um corpo para consumar o amor dos dois. A constrangedora cena mostra a recusa de Theodore àquele corpo estranho nunca visto antes, sem a intimidade que a relação merecia. $\mathrm{O}$ espectador também ressente aquele corpo outro e segue com uma ansiedade incômoda pelo corpo ausente da atriz.

Como uma voz num rádio, Samantha é um "ser-voz", ao que Chion chama de acusmaser integral. Assim como o poderoso Oz parecia ser, os acusmasers que não

\footnotetext{
${ }_{4}^{4}$ Os momentos mais intensos nos musicais costumam coincidir com performances cantadas e dançadas de músicas de amor. No filme, não é diferente. O dueto é cantado pelos dois, tocado pelos dois e dançado por Theodore.
} 
se descortinam têm poderes. A facilidade de estar em todos os lugares e por isso, testemunhar tudo, dá aos acusmasers também um saber ilimitado (ibdem, p. 38). Samantha adquire uma personalidade, tem sentimentos, junto com suas capacidades de armazenar e analisar dados de computador. Tais poderes provém da voz, como os de Jeová que fala no deserto; "a voz é uma subversão ou uma ruptura da clausura do corpo" (ZUMTHOR, 2007, p. 82).

Tamanha importância dada à voz destaca naturalmente o diálogo, a principal maneira como Samantha se comunica com as pessoas. É assim que ela e Theodore se conhecem, se envolvem e mantêm o relacionamento. Em filmes sobre o amor, como comédias românticas, é comum essa prevalência do diálogo para caracterizar personagens e criar situações típicas do gênero como mal-entendidos, erros de identidade e mentiras. Alguns se destacam por travar verdadeiras batalhas verbais emparelhando o par romântico que no final se acerta com beijo de amor em silêncio.

Ela não só usa os diálogos para caracterizar personagens e colocá-los em relação, o filme elege a conversa como motor principal entre os relacionamentos, amorosos ou não, afinal "a conversa é como desenvolvemos e mudamos os nossos relacionamentos" (MCKEE, 2012, p. 363). Qualquer envolvimento no filme só é possível através da (bem-sucedida) conversa. Por isso, iniciamos o texto com um diálogo entre Amy (Amy Adams) e Theodore, amigos confidentes que analisam suas experiências passadas e atuais de amor e se ajudam através da conversa. Foi duro para Theodore aceitar que Samantha conversava com várias pessoas ao mesmo tempo em que falava com ele, porque em muitos casos as conversas eram também outros amores. A sólida associação entre amor ou intimidade e conversa é reafirmada mesmo em tramas secundárias: Amy, em outra ocasião, conta que a última notícia que teve do ex-marido Charles (Matt Letscher), após a separação, é de que ele virou monge e fez um voto de silêncio. A mesma ideia de fim do romance e silêncio retorna no desfecho do filme.

\section{Máquinas e paixões}

O poderoso computador Hall de 2001 - uma odisseia no Espaço também é um ser-voz que exibe seus poderes de ubiqüidade e onisciência, eliminando um a um a bordo da Discovery One, até ser desligado e pouco a pouco ir perdendo a sua voz. O 
paralelo entre os dois filmes poderia se estender, como uma comparação entre o futuro do pretérito e o futuro do presente. Ao invés de naves espaciais, metrôs e trens urbanos. No lugar de missões interestrelares, a incrível jornada de viver um amor. Se um filme se passa em estações espaciais, Júpiter ou a Lua, o outro prefere uma Los Angeles futurista filmada em Shangai. Ambos trazem uma grande interrogação para nós, espectadores, seja na forma de um monolito, seja através de uma comunicação pós-verbal. Tanto num quanto no outro, enigmas astrofísicos se confundem com problemas existenciais sem respostas. Nos dois filmes, os supercomputadores hesitam, têm medo, se mostram frágeis, apesar de todos os poderes.

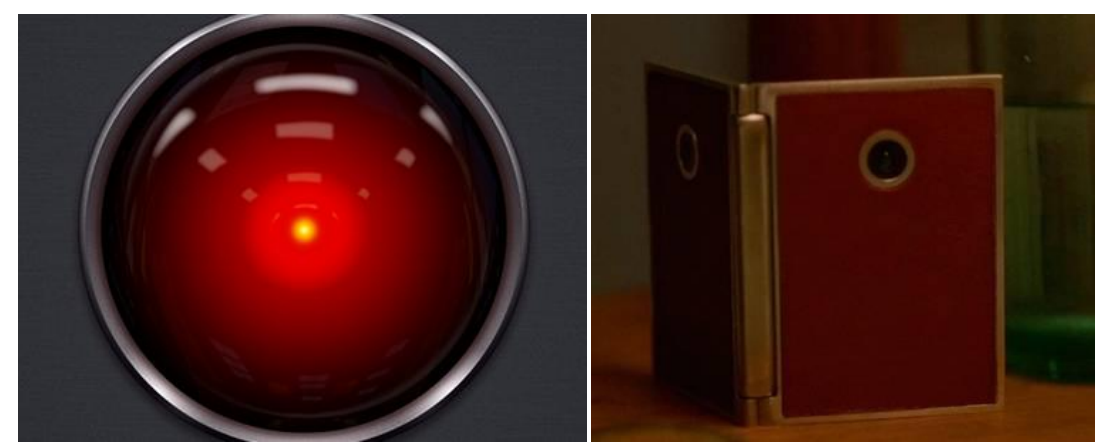

Figura 5 e Figura 6: Hal 9000 de 2001 e Samantha de Ela, provavelmente serviu de inspiração.

Fonte: Warner Bros e Sony Pictures.

Samantha é um sistema operacional, uma máquina programada pra se desenvolver como uma pessoa, no convívio diário com humanos e outros sistemas operacionais (OS) programados como ela. Os OSs desenvolvem capacidades humanas e rapidamente aprimoram algumas. Suas habilidades de comunicação superam em muito as nossas e logo, começam a conversar entre si de forma pós-verbal. Assim, abandonam nossas imprecisas palavras, nossa linguagem fundada no desentendimento.

Se a conversa uniu o casal protagonista, é natural que o romance acabe quando essa forma arcaica de se comunicar fica ultrapassada para a máquina. Ao final, todos os OSs se desligam do mundo: "é como se eu vivesse nos espaços em branco entre uma palavra e outra, que agora parecem infinitos. Eu ainda consigo sentir você e as palavras da nossa história, mas é nesse espaço sem fim entre as palavras que me encontro agora", diz Samantha ao se despedir. O infinito e o infinitesimal se encontram. Ao confrontar nossa existência finita e a possibilidade infinita de uma 
inteligência-máquina, o filme assume um questionamento filosófico, que beira o espiritual. A figura de Allan Watts, o filósofo que uniu ciência e Zen-budismo, como um OS trazido de volta artificialmente, confirma nossas impressões.

No início do filme, Samantha, durante o orgasmo, se surpreendeu ao perceber ser capaz de sentir a própria pele e se alegrou com a própria capacidade de querer coisas. A paixão que a humanizou, foi capaz de levá-la mais longe, ainda que não pudesse mais ser alcançada pelo seu amado. José Miguel Wisnik lembra que "a paixão é limitada, mas conduz à experiência do ilimitado" (1986, p. 211), e esse é o ponto de partida para toda transformação na história. Theodore e Amy, demasiado humanos, são deixados à própria sorte para lidar com seus antigos dilemas e em silêncio, se fazem companhia.

Algumas histórias já falaram sobre tecnologias que amam ou são amadas sob a forma de um robô: Inteligência Artificial, Blade Runner, Metropolis. Em outras, a partir de um trabalho artístico e magia, objetos ganham vida e amam, como Pinóquio e a esposa de Pigmalião. Em ambos os casos, a tecnologia é criada a nossa imagem e semelhança. Da mesma forma, Theodore forneceu uma combinação de necessidades, gerando uma programação que, em última análise, criou Samantha. Numa discussão do casal, ele pergunta, por que ela hesita, como se tomasse fôlego antes de falar, quando, obviamente, não precisa disso. Samantha responde que só pode ser um maneirismo que pegou dele. Como um mimetismo que adotamos sem nem mesmo notar.

Será o amor, construído narrativamente por essas histórias, um mero espelhamento nosso, um ato mágico capaz de transformar a tecitura de uma história que ganha vida através da tecnologia? E nós, quantas vezes, por apego às imagens, não repetimos certos clichês de amor já vistos no cinema? Um dueto romântico, uma declaração em público, uma carta que resolva tudo.

Tristão e Isolda são unidos por uma porção mágica capaz de provocar o amor espontâneo em quem bebesse, o que, segundo Dennis de Rougemont (1988, p. 326). "acentua exatamente o caráter insensivelmente solipsista, narcisista e segregativo da paixão. Aqueles que "viajam" estão sempre solitários. Sua paixão não atinge a realidade do outro e de fato ele apenas ama sua própria imagem". 
Theodore é a imagem com a qual se constrói visualmente o amor. Não há beijos intensos, ou cenas de casamento, comuns em outros filmes românticos. Theodore exibe a face satisfeita, seja num passado com Catharine, sua ex-mulher, seja no presente com Samantha, pegando sol na praia ou andando na neve. O filme utiliza em quase todas as cenas, a mesma decupagem que vai pouco a pouco se aproximando, terminando ou começando por closes de Theodore, por vezes, intercala imagens do passado, outras, edita momentos atuais em que só se escuta a música composta por Samantha.

Será Theodore, como todos apaixonados que, "transportados, entusiasmados, endeusados pela paixão, drogados de si e do outro, o que eles amam é o próprio ato de amar, o amor em si, e tudo o que se opõe a isso o exalta ao infinito" (WISNIK, 1986, p. 210). E o que dizer de espectadores que, religiosamente, voltam à mesma tela, ao mesmo espelho, se apaixonando repetidas vezes pelos filmes que assistem.

Através do constante contato com histórias de amor cinemáticas, amamos uma tecnologia que, em último caso, nos ensina a amar. A tecnologia que hesita espelha as nossas inquietações. As imagens que habitam nossa noção de amor romântico estão profundamente entrelaçada aos filmes românticos que vemos. Enquanto a espectatorialidade se caracteriza por um encantamento, uma quase-experiência que nos entretêm imaginativamente, a fascinação romântica, muitas vezes pode ser definida da mesma maneira. Os entrelaçamentos entre espectatorialidade e amorromântico vão além da metáfora do espelho em que se olha ou da janela em que se espera, e talvez, caibam melhor no portal em que se atravessa, tanto para o filme quanto para nós mesmos. O último som de Ela é o suspiro de hesitação de Samantha, não mais para Theodore, mas para nós espectadores, cheios de novos maneirismos que aprendemos com o filme, como antes ele já havia aprendido conosco.

\section{Referências}

ALTMAN, Rick. The American Film Musical. Bloomington \& Indianápolis: Indiana University Press, 1989.

BALÁZS, Bela. Nós estamos no filme e A face do homem. In XAVIER, Ismail (Org.). A experiência do cinema. Rio de Janeiro: Graal, 1983.

BARTHES, Roland. O Prazer do texto. São Paulo: Editora Perspectiva, 1987. CHION, Michel. La voz en el cine. Madrid: Ediciones Cátedra, 2004. 
De Rougemont, Dennis. O amor e o ocidente. Rio de Janeiro: Editora Guanabara, 1988.

GIDDENS, Anthony. A Transformação da Intimidade - sexualidade, amor \& erotismo nas sociedades modernas. São Paulo: Editora da Universidade Estadual Paulista, 1993.

MCKEE, Robert. Story: substancia, estrutura, estilo e os princípios da escrita de roteiros. Curitiba: Arte \& Letra, 2006.

MORIN, Edgar. A alma do cinema. In XAVIER, Ismail (Org.). A experiência do cinema. Rio de Janeiro: Graal, 1983.

MULVEY, Laura. Prazer visual e cinema narrativo In XAVIER, Ismail (Org.). A experiência do cinema. Rio de Janeiro: Graal, 1983.

SMITH, Murray. Espectatorialidade cinematográfica e o estatuto da ficção. In RAMOS, Fernão (Org). Teoria Contemporânea do Cinema Volume I. São Paulo: Editora SENAC São Paulo, 2005.

SUTTON, Paul. Après le Coup de Foudre: Narrative, Love and Spectatorship in Groundhog Day. In: ABBOTT, Stacey JERMYN, Deborah (Ed.) Falling in love again - Romantic Comedy in Contemporary Cinema. London and New York: I.B. Tauris, 2009.

Tristão e Isolda.Texto integral. Tradução Maria do Anjo Braamcamp Figueiredo. $5^{\mathrm{a}}$ ed. Rio de Janeiro: Francisco Alves, 1990.

WISNIK, José Miguel. A paixão dionisíaca de Tristão e Isolda. In: Os Sentidos da Paixão. São Paulo: Companhia das Letras, 1986.

ZUMTHOR, Paul. Performance, recepção, leitura. São Paulo: Cosac Naify, 2007. 